\title{
Optimizing the Life Cycle of Physical Assets - a Review
}

\author{
E. Pais ${ }^{1,2}$, J. T. Farinha ${ }^{3,4}$, A. J. M. Cardoso ${ }^{2}$, H. Raposo ${ }^{1,3,4}$ \\ ${ }^{1}$ Industrial Engineering and Management, Universidade Lusófona de Humanidades e Tecnologia, \\ Lisbon, PORTUGAL \\ ${ }^{2}$ CISE - Electromechatronic Systems Research Centre, University Beira Interior, Covilhã, \\ PORTUGAL \\ ${ }^{3}$ ISEC - Instituto Superior de Engenharia de Coimbra, Coimbra, PORTUGAL \\ ${ }^{4}$ CEMMPRE - Centre for Mechanical Engineering, Materials and Processes, Coimbra, PORTUGAL
}

\begin{abstract}
Life cycle optimization has been a concern over decades; it has been clear that an asset well-kept will have a longer life with a higher return for the organization; this life cycle depends of several factors.

The standard ISO 55001 defines a set of requirements that, when implemented and maintained, guarantee the good performance of an organization's asset management, responding to stakeholders need and expectations and ensuring the value creation and maintenance as well as a global vision of assets on the Optimizing the Life Cycle of Physical Assets. The organizations where physical asset management is of major importance include all those that involves facilities, machinery, buildings, roads and bridges, utilities, transportation industries, oil and gas extraction and processing, mining and mining processing, chemicals, manufacturing, distribution, aviation and defence.

However, since ISO 55001 is a new standard in the global market, due to its necessity to involve all the organization its implementation becomes difficult; but, it is clear that an organization that certifies by the ISO 55001 is ahead on life cycle optimization because it is part of its requirements; so, what model of life cycle optimization to use? Is there anyone that fits on the ISO 55001? Can an existing one be adapted to be used according to ISO 55001 requirements?

The approaches of this paper bring a literary review of life cycle models used in asset management and their major concerns, this is the beginning to build a model to optimize the life cycle of physical assets including the ISO 55001 perspective.
\end{abstract}

Key-Words: ISO 5500X; Physical Assets; Life Cycle; Optimization; Sustainability

Received: May 12, 2020. Revised: August 21, 2020. Accepted: September 10, 2020. Published: September 18, 2020.

\section{Introduction}

Asset management has been a concern since early years; nowadays, it is one of the most debated topics due to some events on the past decades; on this events we can recall some with major loss, like the Piper Alpha - North Sea (1988), Texas City Refinery Texas (2005), Deep Water Horizon / Macondo - Gulf of Mexico (2010), Amuay Refinery - Venezuela (2012); the common points among all is the lack of risk evaluation and lack of communication. Thus, asset management becomes an important science field because integrates an aim of activities like maintenance, risk, processes, systems, resources management, etc., and also health safety and environment.

ISO 55000 defines asset management as a "coordinated activity of an organization to realize value of assets". According to Hastings [1], the need for asset management as a recognized discipline arises from the complex technical nature of modern systems. Let us take an example from aeronautics field. A contrast can be drawn between, on the one hand, the Wright Brothers Flyer of 1903 (Figure 1), which was the first aircraft to achieve controlled flight and, on the other hand, the modern aeronautics industry.

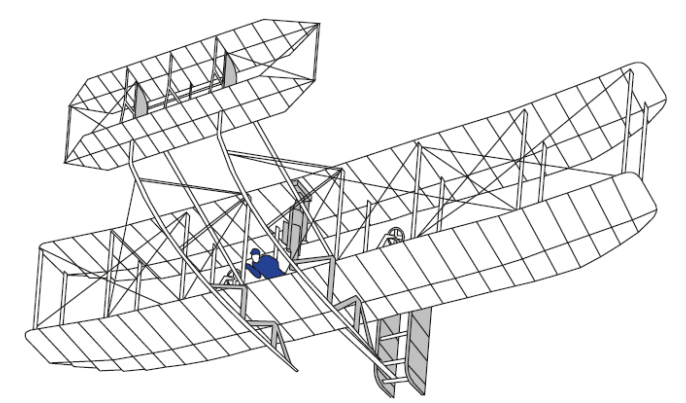

Fig. 1: Wright Brothers Flyer 1903 [1]

Initially, the Wright brothers designed, built, flew, repaired, and financed their own aircraft. They did not need asset management as a separate activity. However, aviation today involves flight operations, engineering, maintenance, finance, human resources, 
and a wide range of asset types on a huge scale. Figure 2 gives some indication of this. It is this vast increase in complexity, across a wide range of industries, which has led to the need for asset management as a recognized discipline.

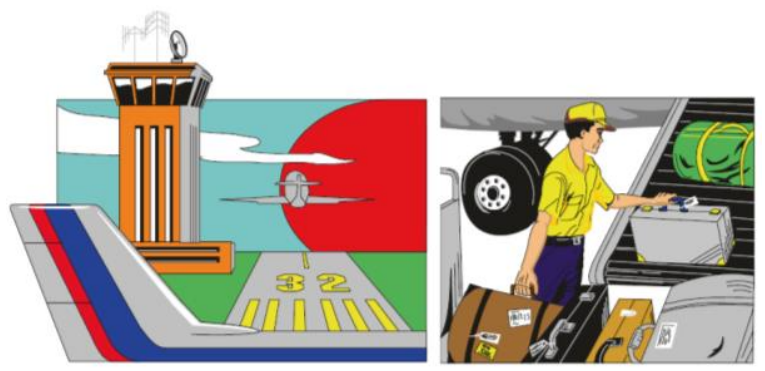

Fig. 1: Modern aviation industry assets [1]

According to Meireles et al. [2], ISO 5500X standards brings a new economic and sustainability cycle. Therefore, the extension of the life cycle of physical assets, its adequate maintenance, reuse, renovation and recycling are strategic variables in its management.

An adequate management of physical assets as well as the optimization of their life cycle are aspects that are determinant from a global sustainability perspective.

In addition, ISO 55001 standard defines the certification requirements, considering that any Organization should emphasize on its Strategic Plan what are the sustainable principles regarding its assets as well as highlighting them in its Strategic Asset Management Plan (SAMP).

When replacing an asset, the Organizations must ensure that the energy consumption of the equipment and its environmental shall justify their replacement. For all these aspects, among many others, ISO 5500X standards can make a decisive contribution to the implementation of a new, more sustainable economy based on innovative management of the physical assets of all we depend [3].

According to Raposo et al. [4], the current competitive environment demands, more and more, of the companies, is a constant search in the improvement of processes in all aspects. Thus, in order to obtain a leading position, companies aim to maintain their standard above the competition.

It is from this perspective that the identification of the optimum moment of substitution of an asset can be the competitiveness of organizations, through the reduction of costs that may be indexed to the maintenance policy used that can extend the asset life.

Companies are increasingly compelled to rationalize their costs, including maintenance costs, which, in the area of energy efficiency, are decisive for the organization's competitiveness. Those responsible for maintenance are therefore also forced to become effective and previously only efficient; the volume and quality of the resources available to them to meet their objectives have become crucial.

The ISO 5500X standards set out to meet this need to manage the life of the organization's physical assets, ensuring the level of competitiveness without compromising the level of excellence of the products / services offered. The ISO 55001 standard proposes a methodology for managing the assets in accordance with the strategic objectives of the organization, supporting decisions to acquire, replace and disposal, aligned with practices that aim at the environmental, social and economic sustainability of equipment and the organization itself.

Van der Lei, et al., [5] say that to overcome the challenges in different asset management, methods have been developed aimed to improve the asset life cycle. Smarter design can lead to improved operation. Likewise, improved operation and maintenance lead to lower replacement costs and may provide the basis for better design. Following this development, the design and operation and maintenance phases have seen a rise in methods and tools for engineering asset management.

Asset management stresses that it is key to consider the whole life cycle of the assets. This development is new as traditionally the improvement of the design, operation and maintenance phases have been separate management tracks. Engineering asset management is an interdisciplinary field that involves research fields like, life cycle costing; maintenance and reliability; risk assessment; change management.

Asset management is seen as a life cycle approach that covers the activities of the organization that undertakes to achieve its goals. This, in contrast to the assets, being something, an organization owns and must maintain. In the life cycle perspective, the management of the asset life cycle is central to the operational success of the organization.

Many times, asset management is described as maintenance, but asset management is an interdisciplinary field and involves research fields as: life cycle costing, maintenance $\&$ reliability, risk assessment, change management.

Hastings [1] describes asset management as a set of activities associated with:

- Identifying what assets are needed;

- Identifying funding requirements;

- Acquiring assets;

- Providing logistic and maintenance support systems for assets;

- Disposing or renewing assets.

So, as to effectively and efficiently meet the desired objective.

From this definition we see that asset management encompasses a broader and quite different set of activities from "maintenance", which is primarily 
concerned with keeping existing equipment in operating condition.

Asset Management according ISO 55001 deals not with isolated activities but with all, where every part is important and must be taken in consideration to have decisions made by a group and not individuals. Because not all changes can be made at the same time, this will lead to prioritizing and may look like a bad decision for a group but it is the better to the all; till this happens optimal asset management decisions cannot be possible; so, what is an optimal asset management decision? This can be a decision that maximizes the value of assets in a long term by aligning them to the organization purposes and objectives and this can change from company to company [3].

So, Asset Management is an umbrella for bringing a lot of existing good practices together, and for filling some of the remaining gaps. It aligns what we do to clear business goals and ensures that the component activities operate in harmony. It requires some sophisticated technical solutions but the most important element of all is the human one - shared understanding, motivation, trust and collaboration to find the best combined outcome, rather than local and short-term self-interest. There is no real doubt that integrated "Asset Management", or whatever it may be called in the future, is becoming a vital business discipline. Yet there is a significant gap between those who "think they already do it", and those who realise the challenges and rewards of the integration/alignment step (and are investing heavily in the merger of new technical solutions, management processes and the human factors).

Those companies that have had the vision and faith to adopt such an approach have universally recognised the tangible benefits - in some cases this has ensured continued company survival, in others it represents their key competitive edge in the next phase of global performance pressure, [6].

This paper is divided in five sections which are the following:

1. The first section is an introduction to the theme;

2. The second section is the state of the art;

3. The third section are proposals;

4. The fourth section is a discussion;

5. The fifth the conclusions.

\section{State of the Art}

\subsection{The Models}

Acording to Amadi-Echendu [7], physical asset management involves a wide range of disciplines and processes covering the life-cycle stages of creating, establishing, exploiting and divesting a physical asset in a balanced manner to satisfy the continuum of constraints imposed by business strategy, economy, ergonomics, technical and operational integrity, and regulatory compliance.

In 1996, Vanier et al. [8] used the Building Envelope Life Cycle Asset Management project (BELCAM) (Figure 3), to provide models, methods and tools to meet these needs, and to assist building researchers and scientists in delivering their evaluation of the service life of building envelope components. This approach incorporates access to information technology such as: The Internet and the World Wide Web; Information technology tools, such as classification systems and product modelling; Life cycle economic principles; Service life and durability research; Risk analysis and reliability assessment; User functional requirement models; and maintenance management strategies. This type of framework for managing data, information and knowledge could be used to predict the service life of other building or construction systems.

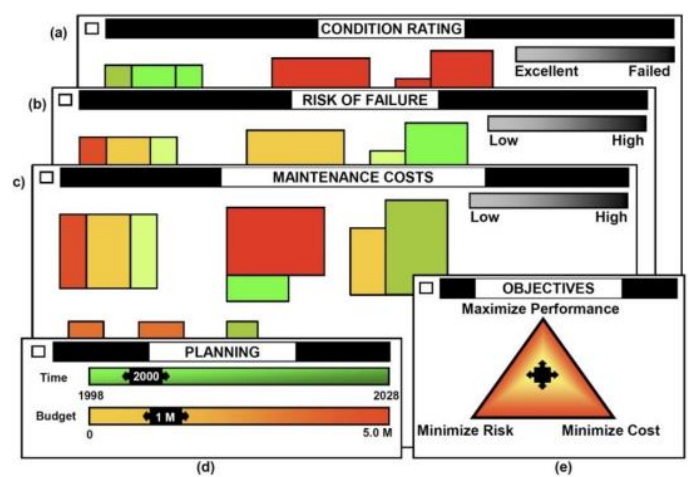

Fig. 3: BELCAM Decision-support Tool [8]

Malano et al. [9] on their work in irrigation and drainage show concern on the hydraulic infrastructure that fulfil most of the service; this infrastructure consists of many individual assets including dams, canals, control structures, pumps, etc., that are usually dispersed over very large areas. Their concern rose as governments embrace economic reform policies that promote the transfer of operation and management functions to irrigators, proper accounting of the cost incurred in providing irrigation and drainage services becomes more necessary. They state that asset management is a process that integrates all these life cycle events with the need to provide an agreed level of service. An asset management program considers all the events occurring over the life cycle of the infrastructure and comprises a strategic and integrated analysis of the life cycle of the infrastructure as part of the continuous organisation management review. The ultimate outcome of an asset management program is to bring into focus the actual cost of owning and operating the infrastructure assets to provide a defined level of service. As such, it provides a clear picture for the organisation and customers of the 
financial implications when providing this level of service (Figure 4).

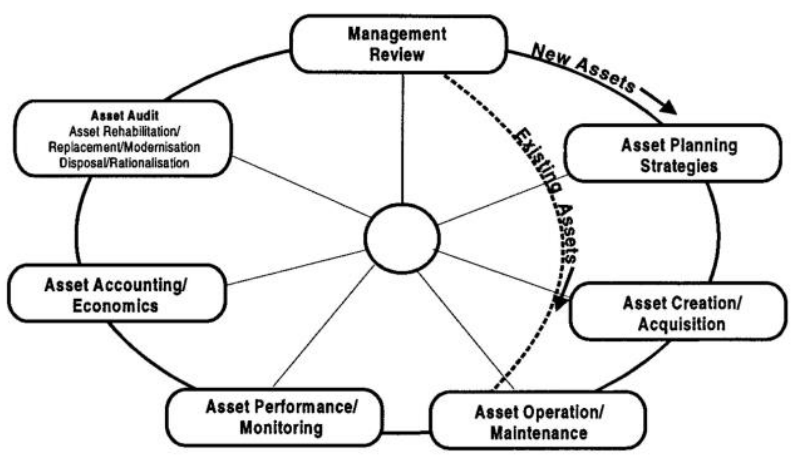

Fig. 4: Elements of an asset management program [9]

In 2005, Malano et al. [10] present an Asset Management Modelling Framework (AMMF) that enables the quantification of on-going ownership costs and operation costs: A Life Cycle Cost (LCC) model for the evaluation of alternative irrigation and drainage asset management strategies.

An asset management modelling framework consists of two main components:

1) A database of assets consisting of geographical location of assets, design features, maintenance records and asset condition and performance;

2) An analysis module which enables the modelling of future asset strategies including the calculation of future liabilities and life cycle asset costing associated with alternative courses of action.

Asset condition refers to the fitness of the asset to perform the function for which it was intended. The condition of assets is the result of several factors including wear and tear, quality of maintenance, age and quality of construction. It is a key measure necessary to determine the residual life of assets and, therefore, the future actions that may be required. It is also important to provide some idea of the overall reliability of the system to deliver the designed irrigation and drainage services. Aspects of reliability are related to the actual condition of the assets and their risk of failure.

Vanier [11] emphasis an assessing decision-support tools for municipal infrastructure planning. $\mathrm{He}$ identifies the extent of the asset management market in North America, addressing the need for decisionsupport tools for municipal-type organizations, identifying the challenges for maintenance, repair and renewal planning faced by asset owners and managers. Integration with existing systems such as Computerized Maintenance Management Systems (CMMS), Geographic Information Systems (GIS) and corporate legacy systems are seen as the largest challenge for developing and using decision-support tools in the area of asset management. The author classifies various stages of implementation for asset management using the six "Whats" questions that asset managers should ask about the status of their portfolio:
1) What do you own?
2) What is it worth?
3) What is the deferred maintenance?
4) What is its condition?
5) What is the remaining service life?
6) What do you fix first?

The activities of a consortium in the area of strategic asset management are introduced with a limited number of decision-support applications, but none provides a comprehensive solution to address the current needs for planning the municipal infrastructure.

On the other hand, Campbell [12] did not profess an asset management speech itself; he describes asset management through a nine steps process as described in Figure 5 and goes a step further in explaining the fundamentals of the asset management process.

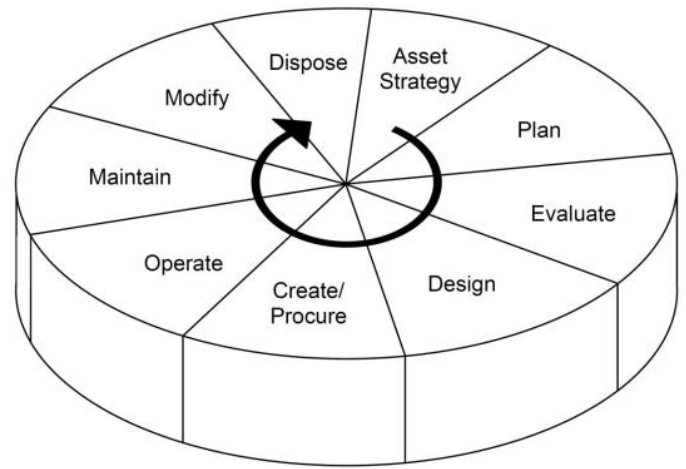

Fig. 5: Asset Management Process [12]

From the South African perspective (Figure 6), the basic asset lifecycle management model is described in the National Treasury guidelines. An asset's life cycle can be defined as the period that an entity can predict by using an asset in an economically effective and efficient manner to promote the entity's provision of services or trade. The National Treasury guidelines further states that the period covers all stages of an asset's life: acquisition; use and maintenance; and eventual alienation. This period is described as the useful life of the asset for the entity and may differ from the physical life of the asset [13]. 


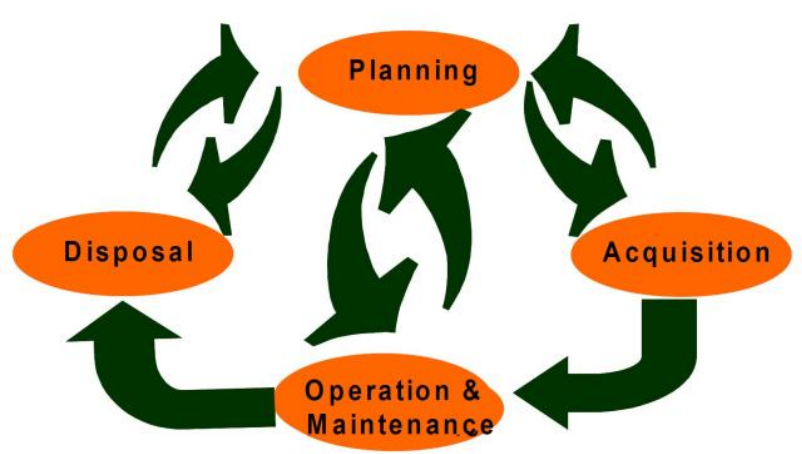

Fig. 6: Asset Life Cycle Management [13]

In 2008, Haffejee \& Brent [14] proposed an integrated Asset Life Cost Management (ALCM) model (Figure 7), derived from an amalgamation of Life Cost Management (LCM) and asset management theories. This integrated ALCM refers to the management of assets over their complete life cycle, from before acquisition to disposal, considering economic, environmental, social and technical factors and performances.

They noted that strategic assets may include nonphysical assets such as intellectual capital, but in terms of the model they proposed, only refers to physical assets.

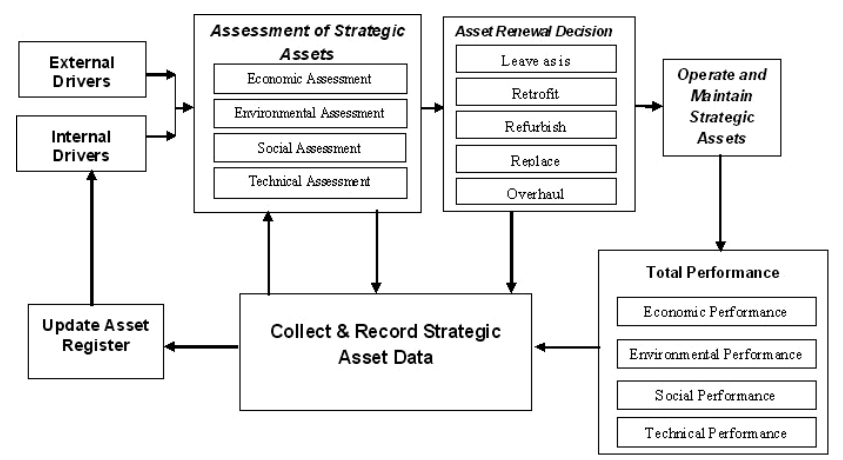

Fig. 7: Integrated ALCM Model [14]

Schuman \& Brent [15] stated that a comprehensive life cycle management approach assures that the processes used across projects are consistent and that there is effective sharing and coordination of resources, information and technologies. All life cycles within a system must be considered, which spans the conception of ideas until the retirement of the entire system. Within the process industry environment, LCM defines the processes for acquiring and supplying system products and services that are configured from the system components of hardware and humans. In addition, LCM provides for the assessment and improvement of the life cycles:

- The development cycle of a system, production plant or facility is initiated with the identification of a need (Figure 8);
- The system, production plant or facility require maintenance and support during their operational lifetime in order to continue to fulfil the identified need;

- A life cycle approach is, therefore, required to reduce operating and maintenance costs, to optimise the productivity of the plant and maintenance and to support the design, which should be engineered concurrently to the performance of the system;

- The requirements regarding the system effectiveness in terms of reliability, availability and maintainability are of equal importance to the functional requirements of throughput, quality, capital cost, schedule, etc. It is critical that the first-mentioned requirements should also be defined during the conceptual phase.

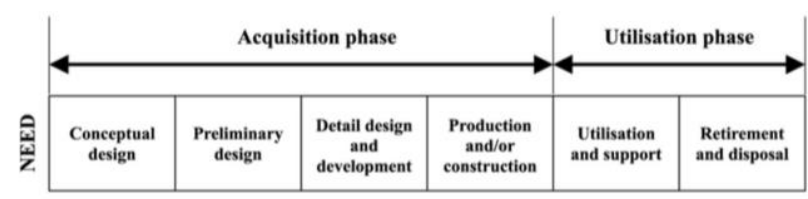

Fig. 8: Life cycle phases of process asset systems [15]

These fundamental concepts must be viewed as part of an effective asset management strategy, which has become a focus area of many companies to acquire and sustain a competitive advantage within a global economy.

Schuman \& Brent [15] proposed an ALCM model for the process industry that integrates the different frameworks that have been discussed above, which is illustrated in Figure 9. Thereby, the model consists of three levels: the project management framework; the asset life cycle; and operational reliability. The model is further described based on the different components of the asset life cycle level.

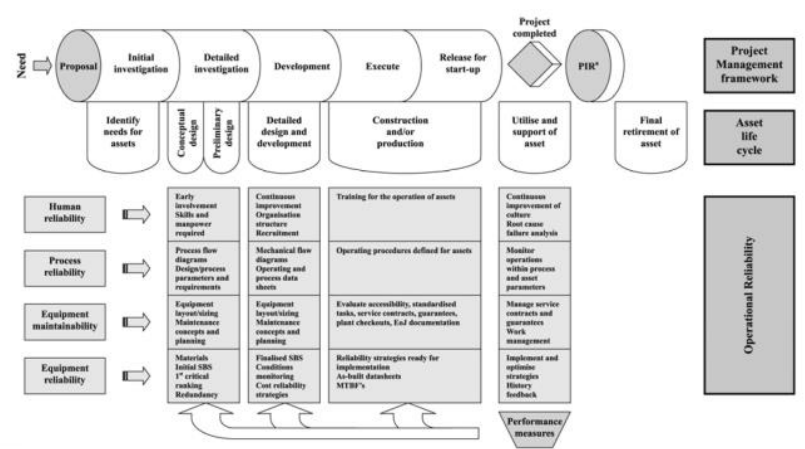

Fig. 9: The proposed asset life cycle management [15]

Farinha [16] sets stages of a physical asset life cycle (Figure 10) that goes from the moment $t_{1}$ (Decision about acquisition) until time $\mathrm{t}_{8}$ 
(Renewal/withdrawal), setting for each stage a set of aspects that must be taken into consideration.

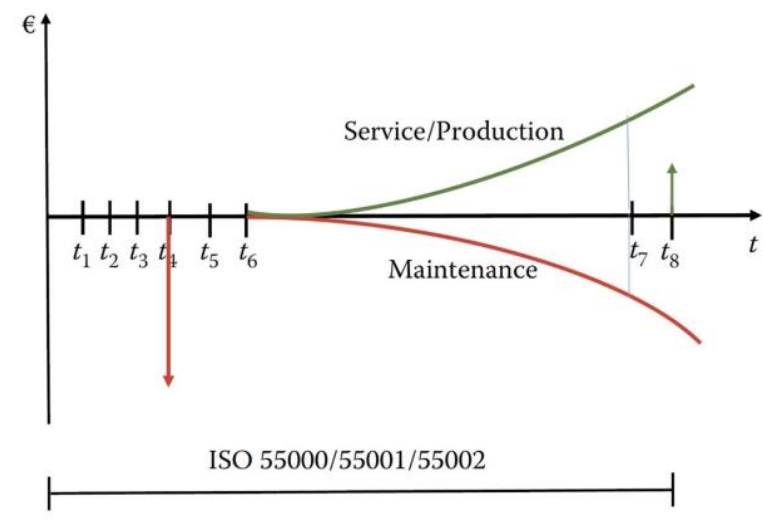

Fig. 10: Stages of a physical asset life cycle [16]
- $\mathrm{t}_{1}$-Decision about acquisition

- $\mathrm{t}_{2}$-Terms of reference

- $\mathrm{t}_{3}$-Market consultation

- $\mathrm{t}_{4}$-Acquisition

- $\mathrm{t}_{5}$-Commissioning

- $\mathrm{t}_{6}$ - Starting production/maintenance

- $t_{7}$-Economic/lifespan issues

- $\mathrm{t}_{8}$-Renewal/withdrawal

Table 1 shows the models and approaches, and their advantages and disadvantages, about Physical Asset Management.

Table 1: Models / Approaches with advantages and disadvantages

\begin{tabular}{|c|c|c|c|c|}
\hline Model / Approach & Author & Year & Pros & Cons \\
\hline $\begin{array}{c}\text { Asset Management } \\
\text { Process }\end{array}$ & Campbell & 1995 & - Nine steps process & - Not a model \\
\hline $\begin{array}{l}\text { BELCAM Decision- } \\
\text { support Tool }\end{array}$ & Vanier et al & 1996 & $\begin{array}{l}\text { - Gathers information only in } \\
\text { order to use in the analysis of } \\
\text { life cycle }\end{array}$ & $\begin{array}{l}\text { - } \quad \text { Based on buildings } \\
\text { - } \quad \text { Don't } \\
\text { mathematical models }\end{array}$ \\
\hline $\begin{array}{l}\text { Asset Management } \\
\text { Program }\end{array}$ & Malano et al & 1999 & $\begin{array}{l}\text { - Introduce elements of an } \\
\text { asset management program }\end{array}$ & 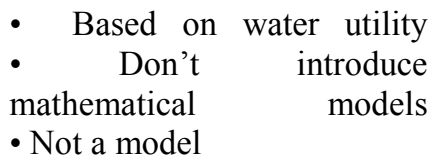 \\
\hline $\begin{array}{l}\text { Asset Life Cycle } \\
\text { Management }\end{array}$ & $\begin{array}{l}\text { National Treasury } \\
\text { guidelines }\end{array}$ & 2004 & $\begin{array}{l}\text { - Sets a framework for asset } \\
\text { management }\end{array}$ & - Not a model \\
\hline $\begin{array}{l}\text { Asset Management } \\
\text { Modelling } \\
\text { Framework } \\
\end{array}$ & Malano et al. & 2005 & $\begin{array}{l}\text { - LCC model is proposed } \\
\text { - Introduce mathematical } \\
\text { models }\end{array}$ & $\begin{array}{l}\text { - Requires lots of data that } \\
\text { may not be available }\end{array}$ \\
\hline $\begin{array}{l}\text { Asset Life Cycle } \\
\text { Management }\end{array}$ & Schuman \& Brent & 2005 & $\begin{array}{l}\text { - Introduce elements of an } \\
\text { asset management program }\end{array}$ & $\begin{array}{l}\text { Don't introduce } \\
\text { mathematical models }\end{array}$ \\
\hline $\begin{array}{l}\text { Asset Life Cost } \\
\text { Management }\end{array}$ & Haffejee \& Brent & 2008 & $\begin{array}{l}\text { - Considers economic, } \\
\text { environmental, social and } \\
\text { technical factors and } \\
\text { performances } \\
\text { - Assets management from } \\
\text { before acquisition to disposal }\end{array}$ & $\begin{array}{l}\text { - } \quad \text { Based on water utility } \\
\text { - } \quad \text { Don't introduce } \\
\text { mathematical models }\end{array}$ \\
\hline
\end{tabular}




\subsection{Life Cycle}

From the European Union Journal ' 'life-cycle' means all consecutive and/or interlinked stages, including research and development to be carried out, production, trading and its conditions, transport, use and maintenance, throughout the existence of the product or the works or the provision of the service, from raw material acquisition or generation of resources to disposal, clearance and end of service or utilisation;

According the same journal there is a concern on the life cycles when contracting; it states the following:

1. Life-cycle costing shall to the extent relevant cover parts or all of the following costs over the life cycle of a product, service or works:

a) costs, borne by the contracting authority or other users, such as:

i) costs relating to acquisition;

ii) costs of use, such as consumption of energy and other resources;

iii) maintenance costs;

iv) end of life costs, such as collection and recycling costs.

b) costs imputed to environmental externalities linked to the product, service or works during its life cycle, provided their monetary value can be determined and verified; such costs may include the cost of emissions of greenhouse gases and of other pollutant emissions and other climate change mitigation costs.

2. Where contracting authorities assess the costs using a life-cycle costing approach, they shall indicate in the procurement documents the data to be provided by the tenderers and the method which the contracting authority will use to determine the life-cycle costs on the basis of those data. The method used for the assessment of costs imputed to environmental externalities shall fulfil all of the following conditions:

a) it is based on objectively verifiable and non-discriminatory criteria. In particular, where it has not been established for repeated or continuous application, it shall not unduly favour or disadvantage certain economic operators;

b) it is accessible to all interested parties;

c) the data required can be provided with reasonable effort by normally diligent economic operators, including economic operators from third countries party to the GPA or other international agreements by which the Union is bound.

3. Whenever a common method for the calculation of life-cycle costs has been made mandatory by a legislative act of the Union, that common method shall be applied for the assessment of life-cycle costs.

\subsection{Importance of Life Cycle Management}

According to ${ }^{2} \mathrm{EN}$ 60300-3-3:2004 products today are required to be reliable. They have to perform their functions safely with no undue impact on the environment and be easily maintainable throughout their useful lives. The decision to purchase is not only influenced by the product's initial cost (acquisition cost) but also by the product's expected operating and maintenance cost over its life (ownership cost) and disposal cost. In order to achieve customer satisfaction, the challenge for suppliers is to design products that meet requirements and are reliable and cost competitive by optimizing acquisition, ownership and disposal costs. This optimization process should, ideally, start at the product's inception and should be expanded to consider all the costs that will be incurred throughout its lifetime. All decisions made concerning a product's design and manufacture may affect its performance, safety, reliability, maintainability, maintenance support requirements, etc., and, ultimately, determines its price and ownership and disposal costs.

Life cycle costing is the process of economic analysis to assess the total costs of acquisition, ownership and disposal of a product. This analysis provides important inputs in the decision-making process in the product design, development, use and disposal. Product suppliers can optimize their designs by evaluation of alternatives and by performing tradeoff studies. They can evaluate various operating, maintenance and disposal strategies (to assist product users) to optimize LCC. Life cycle costing can also be effectively applied to evaluate the costs associated with a specific activity; for example, the effects of different maintenance concepts/approaches, to cover a specific part of a product, or to cover only selected phase or phases of a product's life cycle.

Life cycle costing is most effectively applied in the product's early design phase to optimize the basic design approach. However, it should also be updated and used during the subsequent phases of the life cycle to identify areas of significant cost uncertainty and risk.

The necessity for formal application of the life cycle costing process to a product will, normally, depends

\footnotetext{
2 Dependability management Part 3-3: Application
} guide - Life cycle costing (IEC 60300-3-3:2004) 
on contractual requirements. However, life cycle costing provides a useful input to any design decision-making process. Therefore, it should be integrated with the design process, to the extent feasible, to optimize product characteristics and costs.

According to Juárez [17], making fixed assets investment decision is not easy in the hospitality industry. The investment in assets cannot easily be reversed, and the companies must extract the most profit from them. So, these would expect that the investment made is followed by an increase in their profits. Increasing investment in fixed assets or having a proper development on infrastructures, combined with an increase in the value of fixed assets, do not clearly lead to improvements in financial health, in this industry. The relationship is complex and involves recurrence patterns and independency of the fixed assets or infrastructure value.

For Campbell et al. [18], asset management is many things, done well. It is when a plant performs up to its design standards and equipment operates smoothly when needed. Its maintenance costs tracking on budget, with reasonable capital investment; it is high service levels and fast inventory turnover; it is motivated, competent trades - Most of all, asset management excellence is the balance of performance, risk, and cost to achieve an optimal solution.

Companies, increasingly, face a competitive environment, requiring the development of more efficient and cost-effective operations than ever before. Many asset heavy organizations are under intense pressures such as globalization, shifting markets, outsourcing, and external regulation. All of these factors drive organizations to increase productivity, to reduce costs, and to improve product quality. A $1 \%$ improvement in performance can be worth millions of dollars annually for a manufacturer. In addition, service rates are often regulated, making business survival dependent on efficient management of capital assets using best practices and standards. Organizations are now looking for ways to extend the capabilities of their existing systems.

In the past, asset management was most often described in terms of maintenance management with an exclusive focus on the programs, procedures, and tasks necessary to optimize uptime of an organization's equipment. Today, it requires active life cycle management of the major assets and components from design and inception to disposal, to achieve an edge against competition. A strategic view of asset management first requires new consideration of which assets are to be managed.

According to ISO 55000:2014, "Asset management enables an organization to examine the need for, and performance of, assets and asset systems at different levels. Additionally, it enables the application of

analytical approaches towards managing an asset over the different stages of its life cycle (which can start with the conception of the need for the asset, through to its disposal, and includes the managing of any potential post disposal liabilities)."

According Blanchard and Fabrycky [19], total system cost is often not visible, particularly those costs associated with system operation and support. The cost visibility problem can be called the "iceberg effect", as illustrated in Figure 11.

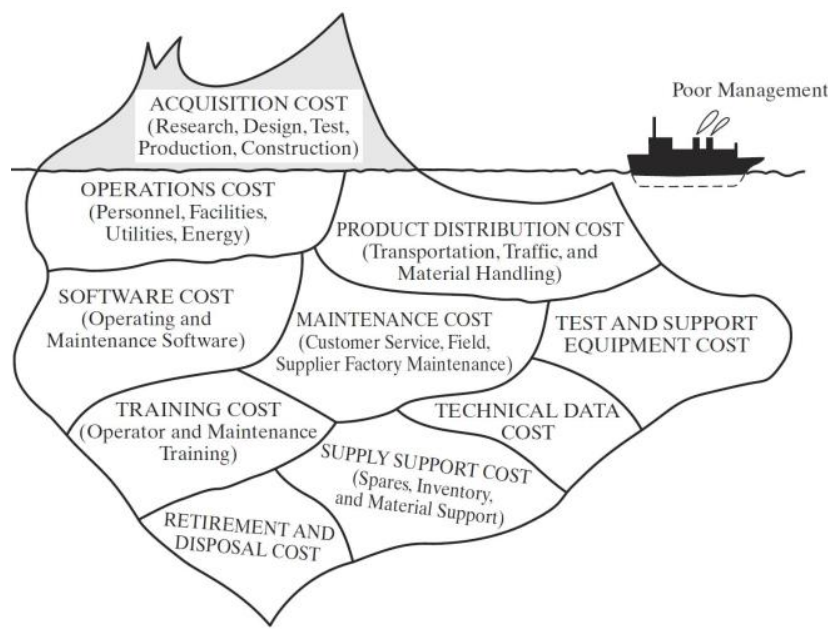

Fig. 11: Visibility of the elements of total LCC [19]

Many of the costs, as we can see, are not visible, and, if we don't have tools to help, it will be a "sailing by sight".

Silva et al. [20] stat that the management of assets in electric power systems has played an important role in the strategic scenario of electric power companies, mainly in the aging of the equipment present in the transmitters and distributors' parks.

As those devices life cycle is extended, it is justifiable to develop methodologies that prematurely identify their health condition, taking into account, not only historical series, but also all available tools of analysis that currently companies own for equipment.

\subsection{Data Quality}

One of the most accepted definition of information quality is given is by Juran et al., [21]: "fitness for use". This definition expresses the fact that information quality is something dependent on the context and high-quality information for a purpose that can be considered low quality for a different purpose.

In order to achieve a good performance in asset management it is strategic to rely on good and reliable information; according to Redman [22], the estimated total cost for poor data quality has been estimated as $8-12 \%$ of revenue range, and $40-60 \%$ of a service organization's expense that may be consumed as result of poor data; those ranges are considered a good working estimate for the cost of poor data quality, and, at the operational level, poor data qualify lowers employees job satisfaction. One Volume 15, 2020 
simply cannot expect the sales manager dealing with customers whose productions have been delayed or whose comfort of an administrative staff dealing with buildings and equipment's problems to exhibit a high level of positive morale.

First, poor quality data compromises decisionmaking; it is a widely accepted maximum that decisions are no better than the data on which they are based, and since any decision of consequence depends on thousands of pieces of data, the chance that decision is based only on good data is extremely small; the slightest suspicion of poor data quality often hinders managers from reaching any decision, and, many times, the most relevant data may be simply unavailable. While all decisions involve some amount of uncertainty, decisions based on the most relevant, complete, accurate, and timely data have a better chance of advancing the organizations goals. Second, at the tactical level, poor data quality makes more difficult to reengineer; many reengineering projects aim to put the right data in the right place at the right time to better serve a customer, making difficult to serve a customer when data is not correct. Finally, just poor data decreases employee job satisfaction, and also increases the mistrust that internal organizations may have one to another; it is made clear that departments in the organizations have needs overlapped, but if each department keeps its own data, sometimes they will find out that they have different data concerning the same issue.

Increasingly, however, those who design databases must support managerial decision-making activities rather than traditional transaction-oriented systems; for a variety of reasons data in such systems may not be of ideal quality - decision makers often must utilize data that are inherently unverifiable, often referred to as soft data. Those charged with designing databases that support decision making, frequently are dealing with imperfect data; so, managers must make decisions in spite of the imperfections of data found in databases; an affective decision-maker can compensate for various deficiencies the data may

\section{Proposals}

\subsection{Asset management implementation}

It's clear that "sailing by sight" isn't the way to take an organization to a good ashore; there must be tools to help on the navigation process. There are many tools, but most of them lack a numerical validation. Econometric, Quantitative models with a mathematical support must be part of any reasonable approach.

To optimize the life cycle of physical assets, the first tool must be the ISO 55001 Standard based on models previously described; it also must be based on EN 60300-3-3:2017 concerning the life cycle costing, EN 15341:2007 regarding the key possess, especially if the decision-maker is acquainted with the data's idiosyncrasies. But this intuitive knowledge is lost, however, whenever data are used by various parties for purposes other than the original, which increasingly is the case, especially as data warehouses become more prevalent. Those potential users who do not possess an intuitive feel for the data may well be forced either to accept the data, which implicitly assumes that all data values are equally valid, or, at the other extreme, to avoid using data whose quality they cannot personally guarantee; these leads that many decision-support systems are not fully utilized for exactly this reason. The most effective format for presenting data-quality information could be a function of the decisionmaking process or strategy; conjunctive decision making assumes that the decision depends upon a known and specified set of criteria, and, for each of these criteria, a minimum acceptable level is established. The decision-maker must choose from among several possible options; in order to make the decision, each option must be evaluated on each of the criteria. An option is acceptable so long as the evaluation on each of the criteria is at least as large as the specific minimum for that criterion; if the evaluation is below the minimum for even one criterion, then that option is not acceptable [23].

According to Woodall et al., [24], maintaining a good quality of information is vital, yet keeping information is a difficult task, and many leading asset management organisations have difficulty in planning and executing successful information quality management practices. According to this approach, it makes sound the asset management decisions, such as whether to replace or maintain an ageing underground water pipe, are critical to ensure that organisations maximise the performance of their assets. These decisions are only as good as the information which supports them; basing decisions on poor quality in formation can potentially result in great losses that can be economic, environmental, human and others.

performance indicators and ISO 31000:2018 to risk management.

There must be built a Strategic Asset Management Plan (SAMP) based on the models presented. The SAMP must have financial and environmental indicators; for example, the balanced scoreboard is excellent to use with SAMP; there are different techniques.

Khodakarami et al. [25] stats that, in different project management processes, there are different aspects of uncertainty. The most obvious area of uncertainty is in estimating duration for a particular activity. Difficulty in this estimation can arise from a lack of knowledge of what is involved as well as from the uncertain consequences of potential threats or 
opportunities. This uncertainty arises from one or more of the following:

- Level of available and required resources;

- Trade-off between resources and time:

- Possible occurrence of uncertain events (i.e., risks):

- Causal factors and interdependencies including common casual factors that affect more than one activity (such as organizational issues);

- Lack of previous experience and use of subjective rather than objective data;

- Incomplete or imprecise data or lack of data at all;

- Uncertainty about the basis of subjective estimation (i.e., bias in estimation).

The best-known technique to support project scheduling is CPM. This technique, which is adapted by the most widely used project management software tools, is purely deterministic. It makes no attempt to handle or quantify uncertainty. However, several techniques, such as program evaluation and review technique (PERT) and Graphical Evaluation and Review Technique (GERT) incorporates uncertainty.

PERT incorporates uncertainty in a restricted sense by using a probability distribution for each task; those uncertainty factors are related with the lack of knowledge about the duration for each task and, as consequence, the total project; because a SAMP differs from different organizations, only in this way we can plan activities that we don't fully know. Instead of having a single deterministic value, three different estimates (pessimistic, optimistic, and most likely) are approximated. Then the "critical path" and the start and finish date are calculated using distributions' means and applying probability rules. Results in PERT are more realistic than CPM, but PERT does not address explicitly any of the sources of uncertainty previously listed. But most of the SAMP's implementation can be supported by the Program Evaluation Review Technique (PERT); using this method, we can have answers for the following questions:

- What is the expected total time to finish the project?

- What is the duration (start and the completion times) for each activity?

- Which critical activities must be completed to reach the estimated project time?

- How much delay can be tolerated for noncritical activities in order to reach the estimated project time?
- What is the cost to speed up a project to meet a targeted completion time?

- What is the probability of completing a project within a given time slot?

- What is the time interval to the project completion?

For more complex SAMP implementations it may be used the Graphical Evaluation and Review Technique (GERT), that was developed to handle stochastic network structure (network with activities that have probability of occurrence associated with them and time to perform activity is a random variable). In GERT branches of the network are described with two (or more) parameters i.e. one, probability that the branch is traversed and time duration. Therefore, it allows for conditional and probabilistic treatment of logical relationships.

Another benefits of GERT scheduling is it is capable of handling iterative activities which CPM and PERT both do not allow, so after collecting data and describing branches of network; one-branch equivalent function between nodes is obtained and this equivalent function is converted into two performance measures of the network, i.e.: (1) the probability that a specific node is realized and (2) The Moment Generating Function (MGF) of the time associated with an equivalent network. Afterwards, inferences concerning the system under study are made from the information obtained.

The GERT approach addresses most of the limitations associated with PERT/ CPM technique. GERT also allows loops between tasks which makes it able to include iterative activities in network. The main drawback associated with the GERT technique is that it requires complex simulation tools to model GERT system, this is one of the reasons to be used only for more complex SAMP implementations [26].

\subsection{Asset management diagnosis}

To help on the implementation of ISO 55001, Pais et al. [27] present a method of diagnosing the state of the organization, that corresponds to a set of surveys in which the evaluation of the responses indicates the position of the company in relation to the application of the standard, the result is a radar map (Figure 12) where can be seen the position of the organization regarding ISO 55001 implementation.

Each question is related with the points presented on the radar chart as follows:

A. Understanding the organization and its context

B. Understanding the needs and expectations of stakeholders

C. Determining the scope of the asset management system 
D. Asset management system

E. Leadership and commitment

F. Policy

G. Organizational roles, responsibilities and authorities

H. Actions to address risks and opportunities for the AMS

I. Asset management objectives

J. Planning to achieve asset management objectives

K. Resources

L. Competences

M. Awareness

N. Communication

O. Information requirements

P. Documented information

Q. Operational planning and control

R. Management of change

S. Outsourcing

T. Monitoring, measurement, analysis and evaluation

U. Internal audit

V. Management review

W. Nonconformity and corrective actions

$X$. Preventive actions

Y. Continual improvement

The use of this tool will help to check where the organization is and in what direction must go in order to implement an ISO 55001 certification.

Raposo et al. [4] presents a importance of the investment analysis in life cycle cost using econometric models, to support this choice he stats that equipment replacement is a broad concept that ranges from the selection of similar assets, to replace existing ones, to the evaluation of assets that act in completely different ways in the performance of the same function, such as more energy efficient equipment.

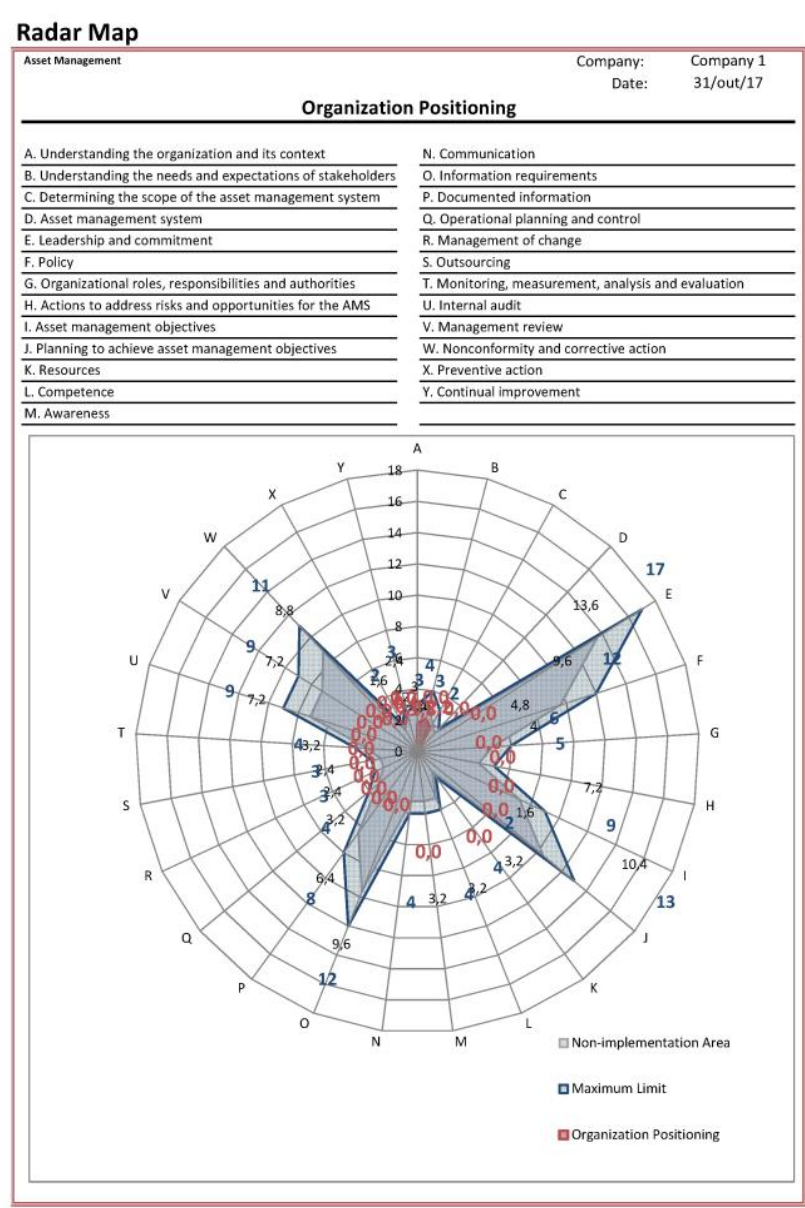

Fig. 12: Radar Map [27]

There are several non-exclusive causes that make replacement equipment economical, being deterioration one of them that is manifested by excessive operating and rising maintenance costs. This subject has been researched by several authors, with interesting results, as is shown, in the field of urban passenger transport, by the references [28], [29] and [30].

There are situations in which, with the change of a current operation, an equipment loses the ability to operate efficiently, that is, the equipment becomes inadequate.

\section{Discussion}

This paper presents a review about the optimization of the Life Cycle of Physical Assets. However, it is based on this short State of The Art review the authors are defining some research questions to guide the next research.

As was described in the previous sections, the optimization of life cycle will rely upon a SAMP, because the actual life cycle assessments are closed upon them and, normally, related with economics; so, to optimize the life cycle, we need to use a broader 
scope where environment and others must be included. On other side, econometric models must be used to proper calculate the equipment and facilities value in each time of their life cycle; only knowing their current value, the decisions can be done regarding their maintenance, recondition or disposal. Life cycle costing is one of the areas in asset management activities where ISO 55001 is the first standard that gathers a broader number of areas to bring the asset management to a higher level.

Some models have been presented on this paper, but none of them show how to implement or use ISO 55001 and, most of them, are based on theoretical concepts without mathematical support, what is fundamental to aid decisions. Most of the models presented have not been validated and, without a validation, it is impossible to know if they are pragmatic enough and, even if they can be applied, they are not easy to use. These difficulties make this tools only available for large organizations with financial and specialized human resources.

This change will be a step forward to increase the sustainability of the organizations as their physical assets life's increase; on other hand, the whole life of the organization will increase due to the good "health" of the same, based on a good maintenance. So, the further works related with this theme must consider different areas, like the ones described on ISO 55001, with a SAMP based on econometric models and mathematical management support with a good balanced scoreboard to pilot the organization.

\section{Conclusions}

This paper took some highlights and some relevant questions about the management of physical assets life cycle, aiming to reduce their cost and to know the state of each asset at any moment. This approach is focused on implementing an Asset Management System (AMS) based on a clear Strategic Asset Management Plan (SAMP). At this moment it is very difficult to implement it due to the lack of information, which is just in a close circle of consultants, that provides services in the area, even many of them understand clearly how an AMS and a SAMP can improve the performance of the assets regarding to their life cycle costing.

The use of ISO 55001 will bring an umbrella over a series of areas that, in many cases, were managed independently, without any integration among them; without this integration the conflicts among the areas were not considered, causing occurrences that had not been taken into account and, sometimes, the risks associated.

\section{References}

[1] Hastings, N. A. (2014). Physical Asset Management. Melbourne, Australia: Springer International Publishing AG. DOI: 10.1007/9783-319-14777-2_1

[2] Meireles, A., Farinha, J. T., Pais, E., \& Raposo, H. (2017). A Economia Circular e a Gestão de Ativos na Perspetiva da ISO 55001. Proceedings of 14. ${ }^{\circ}$ Congresso Nacional de Manutenção. Maia, Portugal.

[3] Pais, E., (2019). ISO 55001 - Diagnosis of the Organization's State. Master Thesis Dissertation, ISEC, Coimbra, Portugal.

[4] Raposo, H., Meireles, A., Pais, E., \& Farinha, J. T. (2017). Análise de Investimento versus Análise do Ciclo de Vida no Contexto das ISO 55000 com ênfase na Gestão de Manutenção. Proceedings of $14 .^{\circ}$ Congresso Nacional de Manutenção. Maia, Portugal.

[5] Van der Lei, T., Herder, P., Wijnia, Y. (2012). Asset Management. Springer Science+Business Media B.V.. ISBN-13: 978-94-007-2723-6. ISBN-13: 978-94-007-2724-3 (eBook). DOI: 10.1007/978-94-007-2724-3

[6] Woodhouse, J. (2001), Asset Management, The Woodhouse Partnership Ltd. Retrieved from: https://www.plantmaintenance.com/articles/AMbasicintro.pdf accessed in 2020.02.11

[7] Amadi-Echendu J. E. (2004). Managing Physical Assets is a Paradigm Shift from Maintenance. Proceedings of International Engineering Management Conference 2004 (IEEE), Singapore, Singapore. DOI: 10.1109/IEMC.2004.1408874

[8] D.J. Vanier \& M.A. Lacasse (1996), BELCAM Project: Service Life, Durability and Asset Management Research, Durability of Building Materials and Components, 7th International Conference on the Durability of Building Materials and Components, 7DBMC: 19 May 1996, Stockholm, Sweden, pp. 848-856. DOI: $10.4324 / 9781315025018$

[9] Malano, H.M., Chien, N.V. \& Turral, H.N. (1999), Asset Management for Irrigation and Drainage Infrastructure - Principles and Case Study. Irrigation and Drainage Systems 13, 109129. DOI:10.1023/A:1006254924281

[10] Malano, H.M., George, B.A. \& Davidson, B. (2005), Irrigation and Drainage Systems 19: 107. DOI: $10.1007 / \mathrm{s} 10795-005-2972-7$

[11] D.J. Vanier (2001), Why Industry Needs Asset Management Tools, Journal of Computing in Civil Engineering, v. 15, no. 1, Jan. 2001, pp. 35- 
43. 3801(2001)15:1(35)

[12] Campbell J. D. (1995). Uptime: Strategies for Excellence in Maintenance Management (1st ed.). Productivity Press, New York. ISBN13: 978-1563270536. ISBN-10: 1563270536

[13] Asset Management Framework (2004). http://www.nwpg.gov.za/HumanSettlements/sit e/documents/policies/Asset $\%$ 20Management $\% 2$ 0Framework\%20v3.3\%202004.pdf, accessed on $10 / 06 / 2020$

[14] Haffejee, M., Brent, A. C. (2008). Evaluation of an integrated asset life-cycle management (ALCM) model and assessment of practices in the water utility sector, Water SA Vol. 34 No. 2. DOI: 10.4314/wsa.v34i2.183651

[15] Schuman, C. and Brent, A. (2005), Asset life cycle management: towards improving physical asset performance in the process industry, International Journal of Operations \& Production Management, Vol. 25 No. 6, pp. 566-579. DOI: 10.1108/01443570510599728

[16] José Manuel Torres Farinha (2018). Asset Maintenance Engineering Methodologies. CRC Press. ISBN-13: 978-1-138-03589-8

[17] Juárez F. (2014), Fixed Assets-Infrastructure and Financial Health in Hospitality Industry: A chaotic effect in Emerging Markets, WSEAS Transactions on Business and Economics, ISSN / E-ISSN: 1109-9526 / 2224-2899, Volume 11, 2014, Art. \#45, pp. 488-495

[18] Campbell, J. D., Jardine, A. K. S., McGlynn, J. (2011). Asset Management Excellence Optimizing Equipment Life-Cycle Decisions. United States of America: CRC Press. ISBN-13: 978-0-8493-0324-1 (eBook)

[19] Blanchard, B. S., Fabrycky, W. J. (2013). Systems Engineering and Analysis. Pearson New International (5th Edition). ISBN-10:1-29202597-2, ISBN-13: 978-1-292-02597-1

[20] Silva I., Flauzino R., Spatti D., Bossolan R., Trevisam B., Trento S. (2019), Asset Management of Power Transformers based on Data Analytics and Statistical Studies, WSEAS Transactions on Power Systems, ISSN / E-ISSN: 1790-5060 / 2224-350X, Volume 14, 2019, Art. \#25, pp. 202-208

[21] Juran, J.M., Gryna Jr, F. M., Bingham Jr, R. S. (1974). Quality Control Handbook. McGrawHill, New York. ISBN: 0-07-033175-8

[22] Redman, T.C. (1998). The Impact of Poor Data Quality on the Typical Enterprise, Communications of the ACM, vol. 41, no. 2, February, pp. 79-82. DOI: $10.1145 / 269012.269025$
[23] Chengalur-Smith, I.N., Ballou, D.P., Pazer, H.L. (1999). The Impact of Data Quality Information on Decision Making: An Exploratory Analysis, IEEE Transactions on Knowledge and Data Engineering, vol. 11, no. 6, pp. 853-864. DOI: 10.1109/69.824597

[24] Woodall P., Parlikad A. K. \& Lebrun L. (2013), Approaches to Information Quality Management: State of the Practice of UK AssetIntensive Organisations, Engineering Asset Management Review 2. DOI: 10.1007/978-14471-2924-0_1

[25] Khodakarami, V., Fenton, N., \& Neil, M. (2007). Project Scheduling: Improved Approach to Incorporate Uncertainty Using Bayesian Networks. Project Management Journal, 38(2), 39-49. DOI:10.1177/875697280703800205

[26] Nepal, B., (2014). Time Management in Projects: Tools, Techniques and Methods. http://v1.prosjektnorge.no/files/pages/635/stude nter/host-2014/specialization-projectbikram.pdf, accessed on 10/06/2020

[27] Pais, E., Raposo, H., Meireles, A., Farinha, J.T., (2019). ISO 55001 - A Strategic Tool for the Circular Economy - Diagnosis of the Organization's State, Journal of Industrial Engineering and Management Science, Vol. 1, 89-108. DOI: $\quad 10.13052 / \mathrm{jiems} 2446-$ 1822.2018 .005

[28] Hugo David Nogueira Raposo, José Manuel Torres Farinha, Luís Andrade Ferreira, Diego Galar (2019). Reserve Fleet Indexed to Exogenous Cost Variables. TRANSPORT. ISSN 1648-4142 / eISSN 1648-3480. 2019 Volume 34 Issue 4: 437-454. DOI:10.3846/transport.2019.11079

[29] Hugo Raposo, José Torres Farinha, Inácio Fonseca, Diego Galar (2019). Economic Life Cycle versus Lifespan - A Case Study of an Urban Bus Fleet. Engineering and Applied Sciences. Vol. 4, No. 2, 2019, pp. 30-43. DOI: 10.11648/j.eas.20190402.12

[30] Hugo Raposo, José Torres Farinha, Luís Ferreira and Filipe Didelet (2019). Economic life cycle of the bus fleet: a case study. Inderscience Enterprises Ltd. International Journal of Heavy Vehicle Systems (IJHVS), Vol. 26, No. 1, 2019. Pp31-54. DOI: 10.1504/IJHVS.2019.097109 


\section{Acknowledgments}

This work was supported by National Funds through the FCT - Portuguese Foundation for Science and Technology, under Projects UIDMulti044632019 - DREAMS, PTDC/EEIEEE/29494/2017, UIDB/04131/2020 and UIDP/04131/2020 and by the European Regional Development Fund (ERDF) through the Operational Programme for Competitiveness and Internationalization (COMPETE 2020), under Project POCI-01-0145-FEDER-029494.

\section{Creative Commons Attribution License 4.0} (Attribution 4.0 International, CC BY 4.0)

This article is published under the terms of the Creative Commons Attribution License 4.0

https://creativecommons.org/licenses/by/4.0/deed.en_US 